\title{
Gender, emotions and fly-in fly-out work
}

\author{
Barbara Pini and Robyn Mayes
}

\begin{abstract}
This paper explores the emotional life of fly-in fly-out (FIFO) workers and their families, through an analysis of more than 500 postings made on an online chat forum for mining families. Building on literature on fly-in fly-out workers and understandings of emotions as socially constructed, analysis shows how posters to the forum, typically women whose male partners are FIFO workers, construct gendered emotional identities for their partners (sometimes referred to as 'Mr Miner'), and for themselves, as 'mining women', 'mining widows' or the 'mining missus'. Inherent in the creation of gendered emotional subject positions is the process of women undertaking emotion work on and behalf of themselves, their male partners and their children. The findings demonstrate the overarching normative dimensions of women's emotional self-transformations in the service of their mining partners' careers and the attendant reproduction of everyday patriarchal relations in the private lives of mining families.
\end{abstract}

Keywords: mining, rural, gender, emotions, fly-in fly-out work 


\section{Introduction}

This paper explores gender, emotions and fly-in fly-out (FIFO) work through an analysis of 513 postings made to chat forums on the Mining Families Matter website (www.miningfm.com.au) from when it was established in February 2010 to December 2011. The popularity of the forums reflects the 'explosion' in the size of the fly-in fly-out labour force that has accompanied the most recent Australian resources boom (Spriggs 2012). While there has been considerable conjecture about the exact number of FIFO mining employees in Australia, media sources point to the dramatic increase in this form of working arrangement (for example, Salt 2012). ${ }^{1}$ FIFO mining operations require workers to perform their work in relatively remote locations, where food and lodging are provided for employees at the work site but not for their families, and where schedules dictate a fixed number of days on-site followed by a fixed number of days off-site, at home. Given the need for FIFO workers to have access to an airport, 'home' would typically be a capital city or a large regional city. FIFO workers and their partners can therefore be understood as part of the large and growing number of couples who 'live apart together' (Holmes 2004), in this case because of the commuting distances to the paid work site. ${ }^{2}$

Despite the growth of FIFO arrangements, academic interest in the subject has been highly circumscribed, reflecting the paucity of independent, theoretically and critically informed social research on mining in Australia, and the dominance of industry sponsored studies on the subject. To date, studies have considered the impact of FIFO work on regional development and on Indigenous people living in rural Australia (Houghton 1993; O'Faircheallaigh 1995; Storey 2001). Beyond this, the multiple dimensions and implications of FIFO arrangements have largely examined industry needs and perspectives. A number of industry studies have focused on the effect of FIFO on workforce turnover to inform strategies to improve FIFO operations (Beach et al. 2003). Other industry-initiated literature (for example, The Chamber of Minerals and Energy Western Australia 2005) has focused exclusively on promoting the economic, social and environmental benefits of FIFO. While studies from non-industry fields such as industrial relations and occupational health have provided a useful antidote to industry-centric FIFO research, the statistical methodology favoured in these studies has often overlooked the complex social and cultural issues surrounding FIFO (for example, Di Milia \& Bowden 2007).

Alongside this research is an additional body of work that has examined FIFO work through the lens of psychology and has drawn attention to the emotional demands this work has upon not only employees, but their partners and children as well (for example, Watts 2004; Kaczmarek \& Sibbel 2008; Pirotta 2009; Taylor \& Simmonds 2009). Again, the socio-cultural context of FIFO has been largely muted in this work, with the emotional aspects of the experience theorised in terms of biology and the individual. As numerous social theorists have explained, such work universalises emotional experiences while 
providing limited understanding of the social environment in which emotions are expressed, shared, judged, affirmed and sanctioned (Lupton 1998; Williams \& Bendelow 1998).

In light of this shortcoming, this paper examines mining families' use of a website, Mining Family Matters, as a way to explore the emotional dimensions of FIFO work through a social constructionist lens. In this respect we depart from the type of psychological studies of emotions of FIFO described above and understand emotions as relational, contextual and infused by relations of power (Anderson \& Smith 2001; Ahmed 2004; Parr 2005). Such understandings of emotions are especially attentive to how social categories such as class, age, ethnicity, disability, sexuality or gender may position people differently and contribute to social inequality. At the same time, we situate the data in terms of the website's potentially regulatory functions, theorised in terms of Michel Foucault's (1988) concept of 'technologies of the self'. In so doing, we draw attention to the ways in which the website and its various discussions operate under the premise of the self transformation of individuals in FIFO families, not only in the 'sense of acquiring certain skills, but also in the sense of acquiring certain attitudes and ways of being as a means to achieve or attain 'a certain state of happiness, purity, wisdom, perfection or immortality' (Foucault 1988: 18).

Technologies of the self are closely related, as Foucault (1988: 18) argued, to 'technologies of power, which determine the conduct of individuals and submit them to certain ends or domination'. As Stanley Deetz (1998: 153) pointed out, what is important here is not so much 'the presence of constraint per se but domination - the naturalization of arbitrary productions and closure of responsive options'. In this respect, as is evident in the data presented below, the Mining Families Matter website and its chat forums naturalise a select range of fundamentally gendered emotional responses to FIFO working arrangements.

\section{Gendering emotions}

What is described as an 'affective turn in social and critical thought' (Thrift 2004: 57) has been greatly influenced by the pioneering work of Arlie Hochschild (1983), who examined the public and interactional dimensions of emotions. Hochschild (1983) explained that we configure our emotions to conform to 'feeling rules' - that is, to the socially sanctioned views about what is and is not acceptable emotionally - and that this constitutes 'emotion work'. While drawing on empirical material from the study of service workers and primarily concerned with the appropriation of emotions by employers, Hochschild (1983) nevertheless argued that 'emotion work' was an everyday performance also undertaken in ordinary interactions outside the public sphere of paid work.

Hochschild $(1983,1990)$ also showed the gendered underpinnings of emotion work, arguing it is more commonly undertaken by women than men, not only in the context of paid work but also in the home. In this respect 
she foregrounded the important body of feminist research examining the intersections between heterosexuality, care and emotions on one hand and entrenched gender inequality on the other. A representative as well as highly influential contribution has been Jackson's (1993: 214) critique of the cultural construction of the emotion 'love' and its role in constituting our subjectivities, including, importantly, our gendered subjectivities:

To be overly emotional for a Western male, particularly within Anglo-Saxon culture, is to bring his masculinity into question. Most discourses around gender, sexuality and love represent women as the more emotional gender: not only as being more nurturing and expressive but also as more deeply emotive beings.

In the decades since Jackson made these observations there have been, of course, significant societal changes and an associated shift in understandings about intimacy and gender. Indeed, in a later paper Jackson and Scott (1997: 567) acknowledged the emergence of new public discourses about women and girls as active sexual agents. However, they also point to the intransigence of more conventional discourses of femininity about women/girls, care and emotions. Thus, despite having their sexuality recognised and celebrated in newly circulating discourses, 'women and girls are positioned as sexual carers who do the emotional work and police their own emotions to ensure that they do not place excessive demands on men' (Jackson \& Scott 1997: 567). Walsh's (2007) study of gender, heterosexual intimacy and emotions among single British expatriates in Dubai adds weight to this thesis. Participants were involved in frequent heterosexual encounters supported by a sense of transience and a rendering of Dubai as a holiday/party space. However, according to Walsh (2007: 527), the British expatriate men disparaged women who expected intimacy with sex, using a range of pathologising terms such as 'clingy', 'dependent' and 'addicted' to mark women who failed to follow the emotional script they advocated. Meanwhile, these men were able to excuse or deflect emotional engagement, as masculinity is commonly understood as inherently unemotional.

Walsh (2007) demonstrates that there are both ruptures and continuities in discourses about emotions and gender in contemporary heterosexual relations (for example, Robinson et al. 2004; Duncan \& Dowsett 2010). In seeking to understand what is occurring feminist scholars have argued for the need to attend to differences between groups of women and men, and to recognise the gendered dimensions of the private/public spheres (for example, Murgatroyd 1989; Mulinari \& Sandell 2009). As Jamieson (1999: 491) contends, couples may approach relationships today with the expectation of 'mutual emotional support and treating each other like equals', but this tells us 'relatively little' about how they may treat each other in their everyday lives in the midst of broader material and discursive gender inequalities. In the context of mining, such inequalities include the fact that the industry has the lowest level of female workforce participation of all Australian industries, comprising fewer than nine percent' (Bryant \& Jaworski 2011: 1346). 


\section{The Mining Family Matters website}

The Mining Family Matters website (miningfm.com.au) was launched with the aim of 'providing practical professional information services and support to Australia's mining families'. According to the first of the newsletters posted to the website, it is 'the brainchild of mining wife and mum-of-two Alicia Ranford who knows that mining is a great industry, but also one that presents unique relationships'. The website is sponsored by the private (for example OZ Minerals, Caltex) and public sector (for example, Primary Industries and Resources South Australia). The website includes an 'Ask our Experts' section with a psychologist, career specialist, health advisor and social worker alongside a shopping guru, who provide advice under a series of questions. Most questions are addressed by the psychologist and cover topics for both the FIFO worker (for example, depression and mine site work) and the FIFO partner (being a FIFO mum), along with information for both partners about, for example, the breakdown of a FIFO relationship and fighting about sex. The 'experts' also include 'Auntie Sandy the FIFO Survivor' and 'The Miner's Girl,' who provide autobiographical narratives of living with FIFO. This part of the website is not interactive. In contrast, a section headed 'Chat Forum', which provides data for this paper, is interactive. The chat forum is divided into nine separate broad topic areas, including mining towns, secrets to a happy FIFO marriage, mining company family initiatives, mining life and the start-your-own discussion section.

\section{Methodology}

Our approach to examining Mining Family Matters is modelled on what Kozinets (2006: 135) terms a 'netnography' or 'virtual ethnography', which he describes as 'a qualitative, interpretive research methodology that adopts the traditional, in-person ethnographic research techniques of anthropology to the study of online cultures and communities'. Mining Family Matters has an open rather than closed discussion list and many visitors take an observational role only, as is indicated by the large number of website visitors $(120,000)$ compared to discussion posts $(513)^{3}$,. The list is in the public domain and individuals posting would be aware that their contribution could be publicly viewed. In this light, we did not seek the consent of those involved in the message boards nor post our intention to use the board for research.

We had been reading posts on the discussion lists and browsing through other sections of the website for a year before we officially began analysis. During this time we made descriptive and analytical notes of particular points of interest (for example, emotional changes, rituals and practices). In a more focused and formal analytical process in December 2011, we examined all 513 posts made to the website from February 2010 to December 2011. They were of various lengths, with nearly a page for the longest and two lines for the shortest, but most were about eight to 10 lines. We then commenced a thematic analysis focusing on the 'emotional content of social relations' (Bondi et al. 2005: 8) 
as communicated in the postings. This process was recursive, with attention to patterns, convergences, differences and marginal themes, coding and cross-coding (Alvesson 2002).

As posters were not required to report their personal characteristics, a full profile of the sample is not possible. However, it appears the majority of posters were female, and either living with or married to a man employed in a FIFO working arrangement. Only three participants identifiable as men had posted on the website. A number of women who gave their age were in their early 20s and new to FIFO. Many of these had two or three very young children. There was also a group of women who were likely to be in their 30 s or 40 s, who had been in FIFO for longer periods of 10 years or more and had older children. Demonstrating the prevalence of FIFO, women who posted lived all over the country in both cities and regional centres and in a range of States. Many of the women said they were in casual work so that they could give priority to fitting in with their partners' mining rosters.

Like emotion researchers who have used personal diaries (for example, Thomas 2007), we found the forum postings a rich data source for revealing the emotional flows of everyday life, but we acknowledge that these are not definitive accounts of the emotional experiences of FIFO workers or their families.

\section{Emotions, FIFO and the 'mining missus'}

From their postings, it is evident that the experiences of women whose partners are FIFO workers differ according to a range of factors. The first of these is the type of roster kept by their partners, which as the discussion list demonstrates, varies considerably within the sector. Talk on the list referred to day length rosters 'on' and 'off' as being 9 days on/5 days off, 8 days on/6 days off, 10 days on/5 days off, and 18 days on/10 days off, as well as week-long rosters 'on' and 'off' moving between 2 weeks on/1 week off, 4 weeks on/ 2 weeks off, 4 weeks on/1 week off, 3 weeks on/1 week off, 2 weeks on/2 weeks off. A number of women who had lived through different rosters referred to some as being more emotionally difficult than others, such as when a roster requires the partner to be away for a month. A second factor shaping women's emotional experiences is the distance between the workplace and the home residence, and the extent to which valuable leave time is used to travel between home and work. A third factor is the availability and efficacy of communication technologies, along with space and time for communication. Some women talk of only being able to communicate with their partners by satellite phone, which means calls tend to be very brief and often end without warning. Others have more readily available personal internet access as well as mobile telephone access, and could make good use of technologies such as Skype.

Despite these differences, across the postings there was a shared, overarching and unifying theme in the construction of the 'mining woman' as an independent, stoic and self-reliant character. Such constructions have been found 
across a range of older studies drawn from interviews with Australian women in mining and mining communities from the 1970s, where women were given titles as 'mining wife' or 'mining town women' (for example, Williams 1981; Gibson-Graham 1996; Rhodes 2005). It is interesting to note the reproduction of this subject position at the beginning of the 21st century on the Mining Families Matters website, although new sobriquets such as 'mining missus' and 'mining widow' and 'FIFO wives' were used by the mining women when talking about themselves. As one posted about the broader community of which she was part, 'Us FIFO wives are a pretty independent and resourceful bunch' and affirmed these were women who could 'cope with anything'. Highlighted through the narratives are characteristics such as practicality, strength and resilience, leading one new member to question: 'How do you all do it????? I've been reading all your stories and I think you all deserve a medal. I hope I can be as strong as you ladies'.

The above posting reflects a broad division between the posters - those new to mining and the FIFO experience, and those whose male partners had worked on a FIFO basis for extended periods. It is also emblematic of the pedagogic and potentially regulatory impact of the discussion list on women with little experience of a FIFO lifestyle. These women spoke of their pleasure in finding the website, often revealing they were searching in the midst of loneliness and despair. They simultaneously expressed gratitude to those with FIFO knowledge and experience, from whom they sought advice and support. Meanwhile, the more experienced FIFO women circulated constructions of mining women as independent, resourceful and strong - and sometimes unemotional. There was a sense of relegating deep emotional reactions to FIFO as something from their past and/or something that was negative and to be avoided. One asserted, 'It has been hard at times trying to cope with everything on my own. Sometimes I felt like giving up and walking away, but that is giving in and I'm not a quitter'. The list creator added:

Being the partner of a miner is not easy. When my now husband and I first met he left for three months in far north Queensland, then ten months after we moved in together (some years after we met) we moved to Perth where three days after we arrived knowing no-one he left for one month on the mine site. I was so lonely! It was so hard! We have since moved another five times, lived in South Africa for two years and now have two beautiful children and hubby does a FIFO roster. But you know what...I wouldn't change a thing! So many opportunities if you can get your head around it all you can really make the lifestyle work for you.

The 'opportunities' of FIFO and being in the mining industry more generally were not enumerated in this posting. Women nonetheless mentioned many positives features of the lifestyle, such as having friends from across Australia (as a result of travel), and having male partners able to attend family-focused day-time functions such as school events in the time they were at home. 
Women's emotional registers of loss, loneliness and uncertainty in the past were often connected to the age of their children. Younger women were advised that things would improve substantially when offspring became less dependent and were able to provide company. Such responses did little (if anything) to challenge the gendered division of labour in the household and/or paid work. This is exemplified in the following two posts from women at different stages of their lives:

I guess I expect him to come home and want to help more with kids/housework and just give me a break and he just probably wants to relax as well. We just clash. Does it ever get easier? Or does anyone have tips on how to make his time at home a happy one?

I think the mums with little kids and babies do it hardest here, but even when my babies were tiny my husband was at work and wasn't able to help all that much. Most of us mums do it ourselves if the truth be told... and we get "help" from our partners here and there.

The above negation of the specificity of FIFO was also engaged when there were emotional concerns raised about infidelity. Women were counselled that this is problematic in all workplaces and not unique to FIFO couples.

While most long-term FIFO women talked of strong emotional reactions to FIFO being in the past, a number shared anecdotes of sadness in the present. Importantly, however, sadness was again transitory and ultimately recognised as irrational and trivial. Illustrative is a posting in which a woman describes her response to a missing dog after the end of a long day:

I just started to cry right there and on the curb. I was tired. It was raining and I still had to feed, bath, bedtime story and tuck in the kids. When I went inside now wet and red eyed my daughter asked what was wrong. I just started to laugh because it was, of course, completely ridiculous to be this upset about the dog who would come back.

In another instance, a member shared that she had been in tears the day her husband left, but then qualified this by writing, 'Looking back now I was a pretty pathetic sight crying into my pan of risotto and when I told my friends they had a good giggle and so did I'. Echoing both the positioning of the 'mining missus' as self-reliant and emotions such as sadness as potentially self-indulgent and requiring regulation through self-ridicule, she reflected, 'I kind of pride myself on being able to cope with just about everything but my birthday is the one day I end up feeling a bit sad'. She concluded, 'I did see the funny side in the morning though' as her five year old and three year old make a mess of the bedroom and kitchen attempting to bring her breakfast in bed.

Ultimately, according to long-term FIFO women, emotions such as sadness and resentment needed to be 'handled', 'dealt with' or 'worked on'. This was demonstrated when a young woman said she had not been able to talk properly 
to her partner for a number of weeks as he was on a satellite phone and calls were very limited. A respondent cautioned her, 'Just be focused and calm about it. Sometimes these things are part of FIFO life and just have to be dealt with'. As a means of 'dealing with' or managing emotions such as sadness, loneliness and resentment, FIFO women shared their strategies for managing their emotions, that is, their 'technologies of self' (Foucault 1988). These included enjoying time to oneself, connecting with other FIFO women, and limiting alcohol intake.

In the postings, there was evidence of a tension between women's expression of pride in their emotional strength and the need to temper this capacity when FIFO men returned home. One woman new to FIFO sought assistance as her husband had been 'warned by a lot of guys on site that she would become too independent and resent him'. Another added:

As for becoming more independent when you have a FIFO or DIDO partner, it's true. My husband says though that he couldn't have married someone who wasn't independent because of his work situation. He needed someone who would be able to deal with things on their own for periods of time. He sees it as a benefit. I do little things though to make sure he still knows I need him. If there are things I need him to do when he is home I write a list.

Those new to FIFO responded to this issue, raising anxieties about potentially becoming 'too independent' so that they no longer want nor need their partner, and/or he no longer feels wanted or needed. As one observed, 'I think it's also hard as like you said we become quite independent due to the circumstances and I think this is hard on them. What man doesn't need to be needed?'.

The FIFO female partner must therefore perform a delicate emotional balancing act of self-transformation, by shaping her emotional capacities around the presence or absence of her male partner in the home.

\section{Emotions, FIFO and mining men}

There were two distinct aspects of the women's postings, in terms of their perceptions concerning the mining men and their emotional experiences and wellbeing. The first was the positioning of the men's work (and life) as having a certain emotional profile because of its geographical location. In forum participants' discussions of men's problematic emotional registers, women referred to them being 'out there', 'miles from anywhere', 'out of civilisation', 'in the middle of nowhere' and 'out in the bush', suggesting a specific profile of the rural as emotionally bereft. As rural scholars have demonstrated, rurality is not merely a material entity but a powerful discursive category which can be imagined as having emotional characteristics which shape the emotional lives of those who are emplaced outside the metropolitan sphere (Parr et al. 2005; Bryant \& Pini 2011). Thus, the affective dimensions afforded to the landscape of the mining camp and mining site as harsh, lacking and tough in the postings 
are mapped on to mining men. What many of the women's postings contend is that the negative emotional consequences of the geographic location are intensified by the hegemonic masculine practices, assumptions and beliefs of mining camp life, such as swearing, drinking and violence. In this respect, in the view of women posters, social constructions of rurality and masculinity intertwine to create a particular emotional profile for the FIFO mining man as emotionally lacking, immature, or inappropriate. Women express this in numerous postings that set up what occurs and is acceptable emotionally on the mine site or camp, and what should occur and would be considered acceptable at home as opposed forms of behaviour. They write:

Behaviour that might seem acceptable and normal in the mining culture is the opposite of what is required in an intimate relationship - full stop!

Try the same poor manners at home and they get divorced. A relationship's needs are more sensitive than that of work culture [...] it takes more effort in the home front.

The much agreed-upon disparate emotional environments of the workplace and the home were found to create particular challenges, as postings to the thread, 'How to make his time at home a happy one' demonstrate. Comments here suggested there was a need for men to be given time to breach the different emotion-spatial contexts of the mining camp and the family home. Again, the former is seen as a place devoid of intimacy - of individuals focused only on functionality and tasks. The latter, on the other hand, is an emotionally charged space, especially when dearly missed husbands and fathers returned home. Women's posts explained how they undertook the work of managing the emotional transition for their partners, and demonstrated that they privileged the men's emotional state over their own.

We have found giving him a day to find his feet helps. He says it's hard after being on your own for work with essentially no affection just head down getting the job done to then come home and have us all smothering him with love.

As well as attending to the men's emotional needs, women also worked to control and contain their own emotions. The challenge women face in holding back their emotions is magnified as male partners prepare to leave and become afflicted with what one poster called the 'going back to work blues' and become emotionally distant.

Numerous women concurred with comments referring to their own practices of giving men 'space'. This was one of what different women referred to as 'rules' - a term which emphasises the normative aspects of the list and echoes Hochschild's (1983: 563) term 'feeling rules' referenced earlier. According to Hochschild (1983), 'rules' are embedded broader power relations structuring what emotions are felt and expressed along with where and why and which emotions are valued and which are demeaned. For the FIFO women 'rules' referred not only to what emotions they could and could not express at 
particular times but also a range of practices which would support the emotional needs of their mining partners. The only interruption to what was otherwise consensus about the need to 'give FIFO men space' emerged when a woman questioned, 'Come on ladies - what century are we living in? Why do they need space? I thought marriage was a partnership?' She continued, 'Perhaps they like the "bloke" lifestyle at the mines, hot cooked meals, nights at the wet mess, watching whatever they want on TV, plus getting a full night's sleep! Gee where can I get a job like that?'

As so often occurred on the website when any seemingly controversial comment was offered, one of the women who established the forum stepped in responding with approval of the idea that marriages are partnerships and that what was required were 'mutually beneficial solution(s)' to a partner struggling. Further, contributions to the chat forums were framed within an overarching (deeply normative) insistence, on the part of the website's 'experts' and in the words of Auntie [sic] Sandy, that 'we are survivors' and that while 'the lifestyle is not easy and does require extra effort' it nevertheless 'does work'. The following posts, typical of the concerns of those new to FIFO arrangements, along with 'expert' responses appearing on the 'start your own discussion' chat forum, exemplified embedded and gendered themes of self-surveillance, disclosure and control among participants, along with 'appropriate' emotional responses and strategies for the mastery of the emotional self central to this 'survival'.

I just don't want to sit here sad wondering what he might be doing there. Is there a high separation rate? Do many men stray while away? I know it's my issue and I need to get over it but I'm finding it hard.

I really love him and I want to support him, but I'm really scared about how tough this will be on our relationship. Does anyone have any tips for me? I really want to be able to support him - last thing he needs is me making things more difficult for him.

Typical responses included:

One of the biggest bonuses of FIFO life is the excitement when they come home. You have to focus on the positives!

Try not to let those doubts get the better of you though ... they can be quite toxic.

Mining is a great industry and you can make it work for you but it does have its challenges! Go back through our psychologist's articles as there is so much great information that can really help make it easier on both you and your husband.

This is not to suggest that women were not supportive of others expressing pain, anguish, fatigue or difficulty. However, while there was a very sympathetic tone to the postings, there was also an emphasis on these emotions being transitory and on the need for them to be appropriately managed. 
The binary of men/women and rational/emotional dominated the discussion list and was rarely challenged. Importantly, however, on one occasion a young FIFO father posted a new thread about 'dads and FIFO', expressed his pain at being away from his young family and asked how other dads coped.

Hi. I'm on a $2 / 1$ roster that I have been working for nearly four years. I have two young kids at home (two year old twins) and I'm finding it increasingly hard to be away from home and I'm starting to question myself a little as to whether I'm doing the best for my family. My first few days back on site are incredibly hard and I know the first few days at home for my partner are hard too. We've just started using Skype which has helped a bit but I was just wondering if any other dads (or mums) out there have any tips on how they cope being back at work and away from their families...cheers.

Disappointingly, there was no response to this message available in the study period, but the posting indicates variation and depth in FIFO men's emotional registers that was not readily conveyed in the women's postings about their own mining men.

\section{Discussion and conclusion}

A range of critics have exposed limitations in Hochschild's (1983) theorising of emotions such as her failure to recognise the potential pleasures of emotion work for women (for example, Wouters 1989), or to acknowledge potential resistance to demands to undertake emotion work (for example, Bolton \& Boyd 1993). At the same time her contribution remains important in illuminating her claim that emotions are linked to particular gendered subject positions. Postings to the website demonstrate that the emotion work of FIFO relationships, like the emotion work of the distance relationships studied by Holmes (2004), 'falls mostly to women'. Moreover, as Holmes (2004: 193) contends, 'distance relating is not always "rational", nor does it always feel like a choice. It is an imperfect response to the gender inequalities embedded with a supposedly rationalised world of work that is disconnected from the realm of human relationships'.

This exploratory paper is necessarily limited in that the data are obtained from a single website and not fully representative of the FIFO population. However, this analysis suggests some important themes for future research about the emotional lives and wellbeing of FIFO workers and their families. The research here concentrated on the voices of women with FIFO partners; clearly, the voices of the FIFO men and those of their children also need to be heard. Of particular importance, we suggest, is the need to understand men's perspectives on the emotional meanings, associations, assumptions and practices of FIFO. Integral to this is an understanding of how men working on FIFO rosters seek to manage their relationships and emotions and those of their partners, while on and off site. Further, these data represent a sanctioned public articulation of 'women's' emotion work in which intersections of class, race and sexuality for instance are inevitably obscured, and this could be expanded upon in future 
research. Also emerging as a further area for analysis is the experience of women who undertake FIFO work. Like the lone father who posted a message, one woman's post asked the community if there were women working FIFO involved in the list. She also received no reply in the study period. Of interest to a study of FIFO women would be an examination of the extent to which they are emotionally censored and who, if anyone, undertakes emotional work on their behalf.

As our analysis has shown, the self-directed transformations and emotional work undertaken by the FIFO women support the gendered requirements of the capitalist mining industry's work practices and values. That is, the need to suppress and subordinate emotions, and to privilege the workplace, are rated above the emotional requirements of the domestic space and the children/ women who are, and continue to be, primarily located in this space. Veterans of FIFO arrangements articulate a journey to self-mastery of loneliness, sadness and uncertainty as they undertake a number of 'operations on their own bodies and souls, thoughts, conduct, and way of being, so as to transform themselves' (Foucault 1988: 18) in order to 'survive' FIFO work practices or make a 'success' of this externally-imposed 'lifestyle'. Significantly, this subordination is presented as necessitated precisely by the emotional incompetence of the 'miner'. Consequently, this paper has demonstrated the overarching normative dimensions of women's (emotional) self-transformation in the service of the mining industry, along with the attendant reproduction of everyday patriarchal gender relations. This in turn requires further examination particularly in terms of the inherent contradictions around the construction of mining women as stoic and self-reliant.

\section{References}

Ahmed, S. (2004) The Cultural Politics of Emotion, Edinburgh, Edinburgh University Press.

Alvesson, M. (2002) Postmodernism and Social Research, Buckingham, Open University Press.

Anderson, K. \& Smith, S.J. (2001) 'Editorial: emotional geographies', Transactions of the Institute of British Geographers, 26 (1), 7-10.

Beach, R., Brereton, D. \& Cliff, D. (2003) Workforce turnover in FIFO mining operations in Australia: an exploratory study, Brisbane, Centre for Social Responsibility in Mining and Minerals Industry Safety and Health Centre.

Bolton, S.C. \& Boyd, C. (2003) 'Trolley dolly or skilled emotion manager? Moving on from Hochschild's Managed Heart', Work, Employment \& Society, 17 (2), 289-308.

Bondi, L., Davidson, J. \& Smith, M. (2005) 'Introduction: geography's "emotional turn"”. In L. Bondi, J. Davidson \& M. Smith (eds) Emotional Geographies, Aldershot, Ashgate. 
Bryant, L. \& Jaworski, K. (2011) 'Gender, embodiment and place: the gendering of skills shortages in the Australian mining, and food and beverage processing industries', Human Relations, 64 (10), 1345-67.

Bryant, L. \& Pini, B. (2011) Gender and Rurality, New York and London, Routledge.

The Chamber of Minerals and Energy Western Australia (2005) Fly-in/fly out: a sustainability perspective, Perth, The Chamber of Minerals and Energy Western Australia.

Deetz, S. (1998) 'Discursive formations, strategized subordination and self-surveillance'. In A. McKinlay, \& K. Starkey (eds) Foucault, Management and Organization Theory: From Panopticon to Technologies of Self, London, Sage.

Di Milia, L. \& Bowden, B. (2007) 'Unanticipated safety outcomes: shiftwork and drive-in, drive out workforce in Queensland's Bowen Basin', Asia Pacific Journal of Human Resources, 45 (1), 100-112.

Duncan, D. \& Dowsett, G.W. (2010) “"There's no teleology to it; it's just about the spirit of play": men, intimacy and "late" modernity,' The Journal of Men's Studies, 18 (1), 45-62.

Foucault, M. (1988) 'Technologies of the self'. In L. H. Martin, H. Gutman, \& P. H. Hutton (eds) Technologies of the Self: A Seminar with Michel Foucault, London, Tavistock.

Gibson-Graham, J.K. (1996) The End of Capitalism (As We Knew It): A Feminist Critique of Political Economy, Oxford, Blackwell.

Hochschild, A.R. (1983) The Managed Heart: Commercialization of Human Feeling, Berkeley, University of California Press.

Hochschild, A.R. (1990) The Second Shift, New York, Avon Books.

Holmes, M. (2004) 'An equal distance? Individualisation, gender, and intimacy in distance relationships', Sociological Review, 52 (2), 180-200.

Houghton, D. S. (1993) 'Long distance commuting: a new approach to mining in Australia', The Geographical Journal, 159 (3), 281-90.

Jackson, S. (1993) 'Even sociologists fall in love: an exploration in the sociology of emotion', Sociology, 27 (2), 201-220.

Jackson, S. \& Scott, S. (1997) 'Gut reactions to matters of the heart: reflections on rationality, irrationality and sexuality', Sociological Review, 45 (4), 551-75.

Jamieson, L. (1999) 'Intimacy transformed? A critical look at the "pure relationship"', Sociology, 33 (3), 477-494.

Kaczmarek, E. A. \& Sibbel, A. M. (2008) 'The psychosocial well-being of children from Australian military and fly-in/fly-out (FIFO) mining families', Community, Work \& Family, 11 (3), 297-312.

Kozinets, R. V. (2006) 'Netnography'. In V. Jupp (ed.) The Sage Dictionary of Social Research Methods, London, Sage. 
Lupton, D. (1998) The Emotional Self: A Sociocultural Exploration, London, Sage.

Mining Families Matter (n.d.) http://www.miningfm.com.au.

Mulinari, D. \& Sandell, K. (2009) 'A feminist re-reading of theories of late modernity: Beck, Giddens and the location of gender', Critical Sociology, 35 (4), 493-507.

Murgatroyd, L. (1989) 'Only half the story: some blinkering effects of "malestream" sociology'. In D. Held \& J.B. Thompson (eds) Social Theory of Modern Societies: Anthony Giddens and His Critics, Cambridge, Cambridge University Press.

O’Faircheallaigh, C. (1995) 'Long distance commuting in resource industries: implications for native peoples in Australia and Canada', Human Organization, 54 (2), 205-213.

Parr, H., Philo, C. \& Burns, N. (2005) 'Not a display of emotions: emotional geographies in the Scottish highlands'. In L. Bondi, J. Davidson \& M. Smith (eds) Emotional Geographies, Aldershot, Ashgate.

Parr, H. (2005) 'Emotional geographies'. In P. Cloke, P Crang \& M. Goodwin (eds) Introducing Human Geographies, London, Hodder Arnold.

Pirotta, J. (2009) 'An exploration of the experiences of women who FIFO', The Australian Community Psychologist, 21 (2), 37-51.

Rhodes, L. (2005) Two for the Price of One: The Lives of Mining Wives, Perth, API Network.

Robinson, V., Hockey, J. \& Meah, A. (2004) “"What I used to do ... on my mother's settee": spatial and emotional aspects of heterosexuality in England', Gender, Place and Culture, 11 (3), 417-36.

Salt, B. (2012) 'Mining's FIFO phantom populations distorting the stats', The Australian, 22 June, http://www.theaustralian.com.au/business/ opinion/minings-fifo-phantom-populations-distorting-the-stats/ story-e6frg9jx-1226404803052.

Spriggs, E. (2012) 'Councils push for compensation as FIFOs increase', $A B C$ News, 13 June, http://www.abc.net.au/news/2012-06-13/councils-call-for-fif o-compensation/4068262.

Storey, K. (2001) 'Fly-in/fly-out and fly-over: mining and regional development in Western Australia', Australian Geographer, 32 (2), 133-48.

Taylor, J. \& Simmonds, J. (2009) 'Family stress and coping in the fly-in fly-out workforce', The Australian Community Psychologist, 21 (2), 23-36.

Thomas, F. (2007) 'Eliciting emotions in HIV/AIDS research: a diary-based approach', Area, 39 (1), 74-82.

Thrift, N. (2004) 'Intensities of feeling: towards a spatial politics of affect', Geografiska Annaler, 86 (1), 57-78.

Walsh, K. (2007) “"It got very debauched, very Dubai!” Heterosexual intimacy amongst single British expatriates', Social \& Cultural Geography, 8 (4), 507-533. 
Watts, J. (2004) Best of both worlds? Seeking a sustainable regional employment solution to fly-in fly-out operations in the Pilbara, Karratha, Western Australia, Pilbara Regional Council.

Williams, C. (1981) Open Cut: The Working Class in an Australia Mining Town, Sydney, Allen \& Unwin.

Williams S.J. \& Bendelow, G.A. (1998) The Lived Body: Sociological Themes, Embodied Issues, London, Routledge.

Wouters, C. (1989) 'The sociology of emotions and flight attendants: Hochschild's Managed Heart', Theory, Culture and Society, 6 (1), 95-123.

\section{Endnotes}

1 The first of the objectives of the current House of Representatives Committee Inquiry into the use of FIFO work practices in regional Australia is to determine the extent and projected growth in FIFO/DIDO work practices, including in which regions and key industries this practice is utilised. The need for data on this subject is clear from a perusal of submissions to the inquiry which cite differing rates of FIFO in the industry.

2 The salient criterion here is work patterns regularly involving living away from home; while we use the acronym FIFO this practice also includes drive-in/drive out (DIDO) and bus-in/ bus-out (BIBO) transport modes. Some posters to the Mining Families Matters chat forum appear to be predominantly FIFO though reference is also made to DIDO.

3 This was to 31 December 2011. These figures were available on the site. 